\title{
Virtual Reality Technology as an Educational and Intervention Tool for Children with Autism Spectrum Disorder: Current Perspectives and Future Directions
}

\author{
Minyue Zhang ${ }^{1}$, Hongwei Ding ${ }^{1, *}$ and Yang Zhang 2,* \\ Speech-Language-Hearing Center, School of Foreign Languages, Shanghai Jiao Tong University, Shanghai \\ 200240, China; zhang.my@sjtu.edu.cn (M.Z.) \\ 2 Department of Speech-Language-Hearing Sciences, University of Minnesota, Minneapolis, MN 55455, USA \\ * Correspondence: hwding@sjtu.edu.cn (H.D.); zhanglab@umn.edu (Y.Z.); Tel.: +1-612-624-7878 (Y.Z.)
}

\begin{abstract}
Virtual reality (VR) technology gains theoretical support from rehabilitation and pedagogical theories and offers a variety of capabilities in educational and interventional contexts with affordable products. VR is attracting increasing attention in the medical and healthcare industry as it provides fully interactive three-dimensional simulations of real-world settings and social situations, which are particularly suitable for cognitive and performance training including social and interaction skills. The worldwide rising trend in the prevalence of autism spectrum disorder calls for innovative and efficacious techniques for assessment and treatment. The article offers a summary of current perspectives and evidence-based applications of VR technology as an educational and intervention tool for children with autism spectrum disorder, with a primary focus on social communication including social functioning, emotion recognition, and speech and language. Technology- and design-related limitations as well as the disputes over the application of virtual reality to autism research and therapy are discussed and future directions of this emerging field are highlighted with regards to application expansion and improvement, technology enhancement, and the development of brain-based research and theoretical models.
\end{abstract}

Keywords: virtual reality; autism spectrum disorder; education; intervention; childhood and adolescence

Autism spectrum disorder (ASD) is a neurodevelopmental condition characterized by difficulties/differences in social communication, interaction, language, cognition, and behavioral activities across a variety of contexts [1]. Although the degree of impairment varies tremendously among individuals with ASD, these symptoms can lead to social exclusion and pose significant obstacles to maintaining and sustaining friendships and employment (in the case of affected adult individuals) [2]. To address the problems, traditional intervention approaches generally require intensive support under the direct supervision of well-trained professionals. However, professional care and amenities are not always accessible to many individuals with ASD due to unaffordable intervention costs and/or lack of available qualified therapists [3], which calls for the development of new and efficacious tools for ASD assessment and intervention. In recent years, there has been a rapid advance in the development of virtual reality (VR) technology and its uses for leisure and education. VR has also emerged as an effective approach in various areas of the health field, such as diagnosis [4], rehabilitation [5], surgical training [6], and mental health treatment [7]. The wide application of this technology has inspired many researchers to consider the potential and effectiveness of implementing VR technology for the assessment and treatment of ASD [8-11]. This article attempts to provide an updated review of the emerging field to summarize the current perspectives and identify future directions.

1. VR as a Powerful Tool: Technology-driven Pedagogical and Intervention Platform 


\subsection{Theoretical Underpinnings and Models for VR Training and Intervention}

Many theories on rehabilitation and education support the use of interactive media like VR, which can not only simulate the real world but also provide enhanced experiences that are fully controlled and better suited for learning and practice. For instance, cognitive rehabilitation theory (CRT), based on neuropsychological and cognitive psychological models [12], is an integrated approach involving individualized training of real-world tasks through a variety of techniques for daily functioning improvement [13]. It emphasizes the significance of the individual's social system, personal and environmental context [14] and acknowledges the complicated interplay of these contexts and rehabilitation techniques [15]. Following these essential ideas, researchers have attempted to develop therapies and build models for clinical rehabilitation and intervention. For example, Dhamodharan, et al. [8] proposed an evidence-based cognitive and occupational therapy using an interactive VR environment. Their model analyzes three levels of decreasing functioning and cognitive impairment in children with autism, including attention, reasoning, emotion, social behavior, language understanding, and decision making, and aims to promisingly improve the mental state of autistic children and their life skills.

In addition to VR application in clinical intervention, many pedagogical theories also support its use as an educational tool in school activities. Classic pedagogical theories including constructivist learning, situated learning, and engagement theory all endorse the idea of VR integration into education [16-18]. The constructivist philosophy considers knowledge to be constructed through learners' interaction with the environment. Situated learning holds that learning is realized through continuous participation in the authentic activities in the community of practice. Similarly, the fundamental idea underlying engagement theory highlights the necessity of learners being meaningfully engaged in learning activities via interpersonal interaction and task completion. In these theories, VR integration is envisioned as the platform that enables full participation and facilitates all aspects of interaction and engagement. Furthermore, newly-advanced theories of pedagogy such as experiential learning and affective learning provide even greater support for the investigation of how VR technologies can be harnessed in education and learning.

The basic idea of experiential learning is to provide a learning environment or context for learners to actively experiment and test the hypotheses conceptualized from their previous experiences, and generate new knowledge and experiences for new situations. It is represented as an iterative learning cycle consisting of four steps, i.e., concrete experience (learners' active experiencing and thinking in a given situation), reflective observation (analysis of observed outcomes of the experiencing), abstract conceptualization (situation understanding and hypothesis proposing), and active experimentation (hypothesis testing through active experimenting in new situations) [19]. Experiential learning has become one of the most widely applied pedagogical theories for VR integration into education, because interactive media technologies, especially immersive virtual environments (VEs), can allow learners to actively experiment and reflectively observe in a safe and authentic environment [20]. VEs can be better suited and advantageous for promoting learning as the VR technology allows flexibility and control to remove competing and oftentimes confusing sources of information from the real-world social and environmental context and manipulate variables such as break intervals and other motivational factors/incentives to solidify learning [21]. The realism of the VEs as a design feature of the technology can also facilitate the transfer of important skills into everyday lives [22-24].

Another important concept in the creation of VR learning environments involves socio-affective mediation. The Cognitive-Affective-Social Theory of Learning in digital Environments (CASTLE) proposes that social cues in the digital materials and environment help activate social schemata in learners while reaping the benefits of enhanced social, motivational, emotional and metacognitive processes [25]. Researchers [e.g., 25] supporting affective learning purportedly introduce the impact of affective factors in the learning process. Kort, et al. [26] developed a model that takes into consideration the interaction between emotions and learning and suggested that if a learner's affective state is 
recognized and responded appropriately, learning will proceed at an optimal pace. Similarly, Ip, et al. [27] proposed a pedagogical model for affective learning, namely, the Smart Ambience for Affective Learning (SAMAL) Model, which considers the interplay between body, mind and emotion during the learning process. Affective learning theories provide solid theoretical support for VR application in learning and education as empirical evidence has demonstrated that VR positively influences the affective experience that learners perceive, enhances their learning engagement as well as their motivation to learn, and ultimately leads to better learning effectiveness [28].

As the target knowledge and skills are often multi-layered with different steps or levels of mastery, scalability or proper stratification for programmatic progress to improve usability is necessary. In recent years, interdisciplinary educators have started to work on practice-based theoretical models of VR in education. For example, Bambury [29] on his website VirtualiTeach updated the Depths of VR Model, which categorizes and differentiates between the different VR experiences available to students and educators. The model contains four progressive levels: Perception, Interaction, Immersion, and Presence. At the Perception level, which is the basic level, learners are relatively passive and their experience needs to be supported and framed by well-considered pedagogy. From the Interaction level and into the Immersion level, experiences become more engaging and student-led, and the potential for creativity and autonomy increases. Experiences at the Presence level are characterized by the sense of "being there" and have the potential to foster a "more visceral, emotive response" in students, which enables the deepest level of learning.

\subsection{VR Answering the Needs of Both Typical and Special Populations}

The powerful theoretical backing reasonably introduces VR into pedagogical and intervention fields. With the diversity of capabilities, VR can satisfy different needs of normal people and the special populations.

For normal people, VR serves as a tool for professional training and school education. In the training for some professions such as pilots, VR-based environments simulating flying scenarios are used in place of real aircraft for lower operating costs and safety considerations. VR technology has also developed to meet the requirements of pilot training including short lag time, rapid update rates, motion and force feedback [30]. In school education, VR technology offers various capabilities that contribute to better learning and education outcomes. It helps learners to visualize abstract concepts and the dynamic relationships between them and allows learners to visit and interact with people and events that are otherwise inaccessible or unfeasible because of time, distance, cost, or safety problems [16].

For the special populations, VR can be developed into an idealized tool for intervention and rehabilitation by providing a real-life but more "friendly" environment. Individuals in special physical or mental conditions may have difficulty caring for themselves or controlling their behaviors and can thus feel awkward in the face of other people. However, many of them have the need to improve social interaction abilities for their daytoday life in the real world. This dilemma can be approached through VR technology that provides a safe and manipulable VE in which intervention can take place in a cutomized and incremental manner at the control of therapists [22,31].

For children and adolescents with special needs, in addition to the interventional advantages [32], VR can offer substantial educational benefits. Education is always a tough issue for atypical children since pedagogical design and frameworks for typical-developing (TD) children are usually unsuitable for them. During the learning process of children with learning disabilities or cognitive and perceptual impairments (including ASD), experience can play a more important role because they are often described as "concrete thinkers" who may find it difficult to comprehend abstract ideas or representations $[33,34]$. Affective factors may also have a larger influence on the learning results of children with special needs as they often suffer from emotion dysregulation and accompanied 
affective problems [35,36]. Therefore, the learning environments for children with special needs should be experience-oriented, context-embedded, and lay great emphasis on the affective consequences and emotional responses. VR-driven pedagogical platforms offer the possibility of meeting these special demands. In virtual learning environments, children with special needs are exposed to diverse concrete experiences embedded in realworld contexts and can learn from mistakes without being discouraged or suffering the real consequences. Moreover, VEs can enable children with special needs to experience and explore in ways that may be impossible for them in the real world, for example, allowing wheelchair users "to see how the world looks from a standing perspective" [34]. VR technology, with the above features and capabilities, then holds the promise to become a uniquely empowering technique in special education.

\subsection{Showcases of Popular VR Products}

VR has been developing rather rapidly, with cutting-edge technology quickly applied to commercial production, making VR products increasingly diverse and more affordable over time [37]. Currently, modern immersive VR environments are generally created by surround-screen projection-based displays, head-mounted displays (HMDs), or boom-mounted displays (BOOMs) [38,39].

Surround-screen projection-based displays, such as the Cave Automatic Virtual Environment (CAVE) [40], usually consist of several projection walls constructed to form an immersive environment and motion trackers that track users' head and body gestures. These installations allow a group of users to share virtual experiences in the same physical environment, which is particularly useful for education in classrooms where teachers tend to deliver VR learning materials to a class of students and keep them engaged in the immersive VE. However, due to the technical complexity of constructing such displays and the stringent requirements for the venue, it is quite difficult to apply them to large-scale general education [41].

VR headsets are among the most common VR devices in the market, ranging from the relatively inexpensive but limited Google Cardboard to more advanced HMDs such as Oculus Rift, Oculus Quest, and HTC VIVE. Google Cardboard is a VR viewer that can be purchased at moderate costs and has been favored by school teachers because it is a stand-alone product that can be easily assembled and has a lower price [42], but its major disadvantage is that the VE created by Google Cardboard is actually a $360^{\circ}$ image or video, where users cannot walk or move to approach surrounding objects. The virtual experience provided by later HMDs is more immersive and real-world-like. Equipped with advanced input devices (e.g., joysticks, gloves, trackers), users wearing HMDs can have a high degree of autonomy in the VE where they can move around and perform various actions in a pretty similar way as the real environment. In addition to the high level of immersion and autonomy, HMDs also have the advantage of being portable and space-saving, which makes them a superior option for large-scale education and training.

Another type of VR display is BOOM, a variation on HMD that is suspended from an articulated arm measuring the head position and is held to the user's face with handles [38]. Compared with HMDs, users do not need to support the display on his or her head and BOOMs provide higher-quality images with shorter lag time and are not susceptible to the influence of magnetic fields, thus enabling fast and accurate tracking [43]. BOOMs are also very convenient for users to switch between the virtual world and the real world. After a user releases the display, another user can observe the same images from the same perspective. Thus BOOMs might provide some benefits for rigorously-designed experiments that require participants to be exposed to exactly the same stimuli. However, they have the disadvantage of restricted operating range due to the space taken up by the supporting arms and are comparatively less widely used for education and clinical practice.

As HMDs provide adequately immersive virtual experience and are convenient to purchase and install, they are considered to be the optimal option for large-scale education and intervention [39] and have indeed been utilized in a considerable number of empirical 
intervention studies on people with mental health disorders (including autism) [44-47]. Some researchers pointed out that when wearing an HMD, the user's vision is totally isolated from the real surrounding world. This may raise concerns about the use of HMDs on the ASD population [48]. Nevertheless, recent studies have obtained encouraging results that individuals with ASD adapt well to wearing HMDs and are able to comprehend, learn, and interact in VEs [49-51]. It is also highlighted that the VR materials and contents used for the ASD population for educational and interventional purposes should not only be adapted to suit the immersive environment but also be combined with appropriate pedagogical design targeting the core symptoms of ASD [39].

\section{VR Technologies and ASD}

\subsection{Core Impairments of ASD and Its Increasing Prevalence}

An impairment is considered to be core if it distinguishes the ASD population from TD individuals and those with other developmental delays [52]. Abundant research on ASD has identified core impairments in a variety of social aspects including social communication and interaction, speech and language [53]. Social communication skills cover a broad range of verbal and nonverbal abilities used in real-life and dynamic social interaction such as emotion recognition, emotion regulation, and eye-to-eye gaze. The ASD population has difficulty understanding others' emotions through visual and/or auditory cues [54,55], fails to regulate emotions appropriately and effectively [35], engages less in direct eye-to-eye contact [56] and shows atypical viewing patterns in social contexts [57]. Speech and language skills, which are crucial for successful social interaction, are also frequently reported to be impaired in individuals with ASD. They demonstrate prosodic deficits such as aberrant use of pitch and stress patterns [58,59] and are particularly weak in the pragmatic use of language for communication, such as poor discourse organization and maintaining [60], difficulty in understanding the speaker-listener relationship [61], and inability to conform to conversational rules [62]. It is hypothesized that these pragmatic deficits, together with emotion processing problems, are related to the fundamental impairments in the domain of theory of mind [53,63], i.e., the cognitive ability to explain and predict human behaviors in terms of mental states such as desire, belief, and intention $[64,65]$. These core impairments in communication and language are found to be universal in children with ASD across ages and ability levels [52,66].

Recent years have witnessed an increasing trend of prevalence of autism in the US, China and other countries. Recent data show that one in 59 8-year-old children in the US is diagnosed with ASD [67]. The newest result for China revealed a similar prevalence of autism in China to western countries, at around 1\% [68], and the autism prevalence in South Korea was reported to be $2.64 \%$ (95\% CI=1.91-3.37) [69]. The prevalence in various countries and regions has shown an increasing trend over time in all age groups [70-72], which highlights a growing need for resources to provide care for the ASD population. The expenditure on a child with ASD, covering therapies, medical care, special education programs, is estimated to be approximately $\$ 17,000 /$ year more than for a child without ASD [73], imposing a heavy economic burden on the family. The current intervention approaches, although fruitful in improving ASD individuals' life skills, are not always available for families due to the high costs, and less expensive intervention paths for the ASD population are required to be developed to benefit families with diverse financial capacity.

\subsection{Advantages of Incorporating VR in ASD Research and Therapy}

Assistive and augmented technology such as VR, with the aforementioned theoretical backing and various commercial products, can offer an effective and inexpensive means for ASD individuals to practice social skills and daily functioning both within and outside of therapy. Given the characteristics of ASD, these capabilities are particularly valuable for individuals on the autism spectrum. 
Treatment on VR platforms is less stressful and would be less likely to increase anxiety in people with ASD. Anxiety and poor stress management are common in children and adolescents with ASD [74]. The social deficits associated with ASD can engender the feeling of anxiety, especially in higher functioning ASD youths who are aware of their social disability, and the overwhelming anxiety might in turn aggregate the social impairments of ASD [75]. For example, social anxiety resulting from unsuccessful attempts on communication and interaction may contribute to ASD individuals' avoidance of social situations and lead to further isolation from their peers [76]. This negative impact of anxiety that tends to accompany real-world social skill practice and may reduce the effect of social communication intervention can be minimized through the employment of VR technology, which allows children with ASD to practice their social skills in real-life contexts without fear of mistakes or rejection that they commonly encounter in real-world face-to-face exchanges [77].

VR technology can be combined with gamified approaches to increase the motivation, attention, and focus of participants with ASD. Attention-deficit/hyperactivity disorder (ADHD), characterized by symptoms of inattention and overactivity, is one of the most common comorbid disorders in people with ASD [78]. Different from TD individuals who attend preferentially to social stimuli such as people, faces, and body movements [79], individuals with ASD show an overall reduced social attention, which becomes severer when the stimuli have a higher social content [80]. The inattention problem often hinders the process of research or therapy that participants with ASD take part in, leaving the work of researchers and clinicians floundering. This could be resolved through the addition of a gamified VR element to current practice since the novelty of VR, together with the playability of gamified design, could arouse among many children as well as adults with ASD a stronger interest in the tasks they are going to accomplish, increase their investment in the training and improve generalization [81].

Research and intervention involving VR gamified design can promote understanding of and support for lower-functioning ASD populations. A majority of existing studies and training programs, though having shown promising results, focus on ASD individuals with average or above-average IQ and exclude individuals with low-functioning ASD [82], so further efforts are required exploring and supporting the ASD population at the lower end of the IQ distribution, which demands more novel and elaborate approaches in experimental and interventional design [55]. Research on lower-functioning individuals can be tricky because the tasks that are manageable for TD participants or higher-functioning ASD participants might imply a higher level of difficulty and demand for lowerfunctioning ones due to their reduced cognitive abilities, which might result in a low task completion rate. This poses great challenges for researchers and clinicians as they are unable to test whether the ability required by the specific task is intact in lower-functioning ASDs and would then hesitate to determine whether such difficulties stem from autism or mental retardation or both [83]. This situation can be ameliorated by the adoption of VR technologies combined with gamified design that promotes task completion through offering concrete, fascinating, and enjoyable dynamic stimuli. Previous attempts on using VR games to teach emotions and on VR music education have reported the ability of children with low-functioning autism to complete VR game-like intervention [82] and recorded pretty high improvement for them [84], demonstrating that VR platforms can be especially beneficial for low-functioning autism children.

It has been well-documented that VR technology can offer considerable educational benefits for children and adolescents with special needs. A substantial proportion of people suffering ASD are in childhood or adolescence. According to the fifth edition of the DSM criteria, the age of ASD onset is "early childhood" [1] and the symptoms usually persist through the school ages and are maintained into young adulthood [85], which renders the education of young people with ASD a primary concern and an intractable undertaking. Given the nature and severity of their disability, learners with ASD require carefully-designed individualized planning to obtain educational success, which brings considerable challenges of including students with ASD in general education classrooms 
[86] and calls for improvement and perfection of the special education system. The educational advantages brought by VR technologies could therefore contribute greatly to the long-term support for the ASD population and would be illuminating for educators and policymakers working on special education services for children with ASD.

Apart from the above benefits for ASD, VR technologies also show superiority as a tool of research and treatment. For research, VR-based experiments have enhanced ecological validity, which is increasingly valued in the assessment of neuropsychological research, especially in the field of ASD [87]. Ecological validity, defined as the degree to which task performance corresponds to real-world performance [88] or the degree to which task performance predicts problems in real-life settings [89], has been viewed, to some extent, to conflict with the maintaining of experimental control [90]. Researchers supporting naturalistic approaches hold that many psychological assessments that use simple and static stimuli are ecologically invalid and are unable to generalize beyond restricted laboratory settings [91] while those emphasizing precise laboratory-based control argue that the ecological research approach lacks experimental control and the internal validity that are needed for scientific progress [92]. The tension between experimental control and ecological validity could be alleviated through the integration of VR, which allows precise presentation and control of dynamic perceptual stimuli in ecologically valid scenarios, thus increasing the generalizability of the findings whilst maintaining the same level of control as laboratory-based experiments.

Intervention programs employing VR techniques allow repeated practice and exposure, which is a key element in treatment [44]. In interventions such as social communication training, it is rare that participants successfully acquire the social interaction skill after practicing it only once. Compared to other therapeutic tools that might instruct participants to learn and respond in a rote manner, VR interventions provide the opportunity for repeated practice in dynamic social exchanges [93] and help participants learn by experiencing instead of memorizing. Additionally, on VR platforms, tasks and stimuli can be presented repeatedly and consistently without fatigue [94], avoiding the problem that usually accompanies task repetition by human tutors/instructors [95].

\subsection{Potentials of VR for Investigating Social Interaction}

Among possible applications, the one that receives particular attention from ASD researchers and therapists is the VR-based investigation of social communication and interaction, where ASD individuals tend to be especially impaired. VR offers great potential for social communication research and intervention as it can provide customized authentic scenarios and interlocutors, which are essential in real-life social communication, as well as the sense of being present at the scene of communication.

The social scenarios and contexts replicated in VEs can be carefully designed and controlled at the will of researchers and therapists to create whatever type of environment they want. For various research purposes, features of the real world can either be omitted, enhanced or diminished, social relationships can be emphasized or modified, and the qualities and quantities of surrounding objects can be highlighted or weakened, increased or reduced [34]. The possible social scenarios that can be created through VR are arguably unlimited [96], including social introductions, initiating conversation, meeting strangers/friends, negotiating with a salesman, job interview, working with co-workers and managing conflict [44].

Virtual humanoid representations of people involved in the social scenarios, referred to as "avatars", can be designed to serve as communicators that carry out social communication with the user and give him or her hints on the communicational rules, and as facilitators that offer the user positive reinforcement upon his or her successful attempt to communicate or encourage further practice when the user makes mistakes [97]. The avatars can also be manipulated according to the requirements of researchers and clinicians; for example, the clinician's voice can be morphed by software to sound like a young boy in order to match the avatar's demographics [44]. Moreover, with the aid of artificial 
intelligence (AI), completely virtual characters can be created without the need for a therapist.

The sense of being present, which is positively correlated with the level of immersion [98], also contributes greatly to the potential of using VR for the investigation of social communication and interaction. Practical application is indispensable for the training of social communication skills, with the benefits of intervention usually reduced when exposure to real-world social interactions is absent or inadequate [99]. Individuals with autism have reported a desire for more real-world practice after learning social communication skills in clinical intervention because they sometimes find it difficult to understand a social phenomenon until they see or experience it in a real-world setting [99]. Practicing a learned skill in a real-world context and being successful in that situation would also build confidence in people with ASD and help reduce their social anxiety [99]. Modern VR technologies and products including surround-screen projection-based displays like the CAVE and HMDs like Oculus Rift, with multisensory (e.g., visual, auditory, and tactile) congruent cues in the VEs further enhancing the sense of presence [98], all enable a fairly high level of immersion, rendering them viable tools for study and training of social communication skills.

\section{Recent Applications of VR Technologies to ASD Assessment and Intervention: Evi- dence-based Practice}

VR technology gains theoretical support from rehabilitation and pedagogical theories with powerful and diverse capabilities. When it is instantiated in accessible and affordable commercial products, VR is a superior alternative technique for ASD research and therapy and a promising methodological tool to investigate and improve social communication and interaction skills. The promising prospect of technology-driven pedagogical and intervention platforms has prompted researchers to integrate VR technologies into ASD assessment and intervention, with success, especially in terms of social communication deficits. This section will illustrate recent evidence-based applications of VR technologies to ASD research and treatment, with a primary focus on the social aspects including social functioning, emotion recognition, and speech and language.

\subsection{Social Functioning}

Problems in social functioning (e.g., unemployment, impaired social skills, low social motivation, high social anxiety, social avoidance), are common in the ASD population $[100,101]$. There has been some clinical evidence that VR-based systems can have an increasingly positive impact on the social functioning of individuals with ASD [102]. With the aid of assistive technology, especially VR, participants with ASD showed improvements in social task performance [103-105], communication ability [106], sensitivity to social contingencies (i.e., the other's responsiveness to one's own behavior) [107], social competences and executive functions [108]. There is also evidence that in real-time, computermediated social space, people with ASD could perform social tasks equally well as controls, indicating that the use of VR interfaces could help compensate for the social disabilities of people with ASD [107].

In recent years, investigators have been developing VR agents, systems, and platforms to offer social functioning training to people with autism. For example, Bernardini, et al. [109] created an autonomous planning-based agent called Andy that inhabits a VE designed for real-world use at home and in schools. This agent is the main component of the Intelligent Engine of ECHOES, a serious game built to help young children with ASD acquire social communication skills [110]. In the game-like intervention program, Andy the agent is always positive, motivating, and supportive and plays a diversity of roles including a tutor who delivers visual and organizational support for ASD children, and a peer who provides them with customized interpersonal support and exposes them to positive interactions. The system together with the agent has been deployed in five schools in the UK and was proved to be effective in improving social behaviors of ASD children in 
an eight-week intervention study involving 19 children with autism [109]. Autonomous virtual agents such as Andy could contribute to the intensive one-on-one support needed by ASD children, easing the demand for such support from clinicians and parents [109].

Considerable efforts have been made to alleviate the employment problem of individuals with ASD through VR-driven intervention systems. Burke, et al. [111] created a Virtual Interactive Training Agent (ViTA) system to offer practice in job interview skills required in interview conditions at various difficulty levels. The system includes six virtual human agents of varying ages and ethnic backgrounds, who can exhibit soft-touch, neutral, or hostile dispositions when asking 10 to 12 interview questions, and seven situational contexts such as business office, hotel lobby, and warehouse breakroom, according to participants' specific employment interests. In a preliminary study, the ViTA system has enhanced job interviewing skills in 32 participants with autism and developmental disabilities, with their face-to-face interview outcomes improved significantly after training, demonstrating its effectiveness as a tool for preparing young adults with autism for employment interviews [111].

Similarly, Smith, et al. [112] developed Virtual Reality Job Interview Training (VRJIT), a program providing VR-simulated repetitive job interviews grounded on hierarchical learning, to help facilitate job interview skill training for people with neuropsychiatric disorders. Targeting eight job-interview performance domains such as conveying oneself as a hard worker and sounding easy to work with, the system provides repeatable VR interviews for trainees to interact with a virtual human resources representative, offers them instant feedback to improve their responses, returns scores on key dimensions of performance, and allows review of interview responses. The feasibility and efficacy of VRJIT have been assessed in a single-blinded randomized controlled trial involving 26 participants with autism, the results of which suggested that finding it easy to use and enjoyable, individuals with ASD showed improvements in interviewing skills after receiving training on the VR-JIT system [113] and achieved better vocational outcomes [114].

Another VR-enabled program targeting the employment issue was designed by Strickland, et al. [115], called the JobTIPS program, which offers five sections to guide trainees with ASD through the process of determining career interests, finding a job, getting a job, and keeping a job, and also provides other employment-related topics like leaving a job. Results of a randomized controlled study on 22 participants with autism revealed that ASD individuals completing the JobTIPS employment program showed enhanced job interviewing skills and significantly more effective verbal content skills. Nevertheless, the author pointed out that their program was more effective in teaching "content" (i.e., producing appropriate verbal responses to the interview questions) rather than "delivery" skills (e.g., posture, eye contact).

Kandalaft, et al. [44] focused on more comprehensive aspects of social functioning and developed the Virtual Reality Social Cognition Training (VR-SCT) intervention, a semi-structured, manualized intervention that offers VR-based dynamic practice of meaningful social scenarios for young adults to improve social cognition, social functioning, and social skills. Scenarios in various social contexts were constructed to simulate common real-life social situations including meeting new people, negotiating financial or social decisions, dealing with a roommate conflict, and interviewing for a job. A feasibility study involving eight young adults with ASD [44] and another involving 30 ASD children and adolescents ages 7-16 years [93] were conducted to examine the effectiveness of VRSCT and found that after 10-session VR-SCT intervention, there were significant increases in ASD participants' social and occupational functioning in real life as well as a series of social cognition measures, demonstrating positive impacts of the VR-enabled social skill training program on a wide range of social functioning and social abilities in individuals with ASD across ages. The treatment effectiveness has been further verified by recent investigation on the neural mechanisms of response to intervention in participants with autism receiving VR-SCT, which discovered that such interventions are not only useful in improving social cognition and social skills in individuals with ASD, but also contribute 
to the strengthening of underlying brain networks that support their higher social functioning capacity [116].

In addition to the above VR social skill training systems, many other VR-driven platforms have also proved to be efficacious in enhancing social functioning and social understanding in ASD, such as Virtual Environment for Social Information Processing (VESIP) [117] and collaborative virtual environment (CVE)-based social interaction platforms including iSocial [118] and CVE-based puzzle games [119-121].

\subsection{Emotion Recognition}

The difficulty in recognizing and understanding emotional expressions through multiple cues is one of the fundamental social impairments in the ASD population [122,123]. Children with ASD often show an atypical emotional development from TD children, manifested as a lack of empathy with other people and failure to react emotionally to other people's states of mind [124]. Learning emotion recognition in VEs could remove such emotional barriers and obstacles for the ASD population, as VR training programs have been proved to be particularly helpful regarding emotion recognition improvement in individuals with ASD. For example, previous studies have reported enhanced behavioral performance [44] as well as neural predictors of change [116,125] in emotion recognition and theory of mind in participants with ASD after they completed the VR-SCT program. Similar results were obtained by Ke and Im [126] who observed a consistent and obvious increase in ASD children's perception of emotion from facial expression and posture cues after a VR-based social interaction program and Ip, et al. [127] who documented significant improvements in emotion recognition in over 100 school-aged ASD children after training completion in a CAVE-like immersive VR-enabled system.

In terms of emotion recognition, the level of immersion in the VE could influence the intervention effect. Lorenzo, et al. [124] conducted a randomized controlled study in which they designed an immersive virtual reality system (IVRS) to train and improve the emotional skills of 40 children with ASD. Their results revealed that compared with the use of desktop VR applications, participants showed more appropriate emotional behaviors in the immersive VE and there was a significant improvement in their emotional competences after IVRS training. This finding is corroborated by the results obtained by Schwarze, et al. [128] who found that VR settings are motivational and useful for individuals with ASD to learn emotion recognition, especially under the condition that similar traditional approaches were transferred to a virtual context, e.g., virtual emotion cards. Furthermore, owing to the high immersion of VR-HMD technologies that provide an enclosing, three-dimensional and 360-degree environment for emotion recognition learning, children with ASD were observed to start behaving in an "extroverted" way in their interaction and learning activities [128].

A few recent studies have been attempting to integrate VR technology with dynamic psychophysiological signals to improve intervention approaches regarding emotion recognition. Lahiri, et al. [56] developed a VR-based dynamic eye-tracking system called Virtual Interactive system with Gaze-sensitive Adaptive Response Technology (VIGART) that can deliver individualized feedback according to the user's dynamic gaze patterns during emotion recognition training. The system contained five social communication scenarios where the avatars narrated their experience on various topics such as food, sports, travel, etc. Results of a usability study with six ASD adolescents confirmed that the VIGART can record dynamically eye physiological indexes, enabling objective measures of the user's emotion recognition capability that could in turn guide the refinement of intervention strategies [56].

Modugumudi, et al. [129] conducted an electrophysiological study of two groups of autistic children (ten in each) receiving an intervention program with and without CVEs as assistive technology to see whether children with autism could recognize basic emotions effectively in CVEs. The results showed that an emphasized early emotion expression positivity component at around $120 \mathrm{~ms}$ latency was identified for the CVE trained 
group, which clearly distinguished it from the trained-without-CVE group, indicating that children with autism had a significant improvement in emotion recognition owing to the CVE-based intervention.

Incorporating both eye physiological indexes and electrophysiological signals, Bekele, et al. [130] designed and developed the Multimodal Adaptive Social Interaction in VR (MASI-VR) system that facilitates individualization and adaptation for ASD emotion recognition intervention. The system presents controlled facial emotional expressions within conversational social contexts, tracking eye gaze as well as collecting in a synchronous manner electroencephalography (EEG) data associated with emotion recognition while the users are receiving emotion recognition training and performing the emotion recognition tasks pre- and post-training. The viability and efficacy of this system have been verified through a randomized controlled study with 12 children with ASD, supporting the idea of using task performance and eye gaze, and possibly other psychophysiological data, to enable real-time adaptation of ASD intervention in VR-based training systems [130].

Besides the above breakthroughs in terms of VR-enabled emotion recognition training, researchers have also sought assistance from VR technology to enhance the understanding of how individuals with ASD perceive and handle emotional expressions. For example, Kim, et al. [131] employed a novel measure called the VR emotion sensitivity test (V-REST) [132] to examine emotion perception and interpersonal distance in ASD with the aid of a joystick. While identifying the emotions expressed by virtual avatars, participants could position themselves close to or away from the avatars through the joystick. The study discovered that compared to TD children, children with ASD approached positive happy expressions significantly less, which suggests that children with autism might display atypical social-approach motivation or are less sensitive to the reward of positive socio-emotional events [131]. These results call for revision and updating of the social-motivation model of ASD [133,134].

\subsection{Speech and Language Training}

The ASD populations often have delayed or impaired speech and language abilities, affecting both production and perception, which adds to their communication barriers [135]. Compared to the substantial efforts on VR-based training of social functioning and emotion recognition, less attention has been paid to applying this technology to speech and language therapy in ASD. The majority of the existing research and practice focuses on teaching discrete language components such as vocabulary, grammar, semantics, and pronunciation, with the pedagogical and interventional platforms still limited to non-immersive VEs such as desktop VE and augmented reality (AR).

A computer-based language-tutorial program that has been inspiring for later attempts in this area is the virtual talking head called Baldi, developed by Bosseler and Massaro to train vocabulary and grammar knowledge for ASD children [136]. Implemented in a Language Wizard, Baldi allows easy creation and presentation of language lessons concerning identifying pictures and producing spoken words. An evaluation study was conducted to assess the effectiveness of this computer-animated tutor in vocabulary training and indicated that with the aid of the virtual agent, children with autism were able to learn language skills and could transfer the learned vocabulary in a new environment outside of the program [136].

Saadatzi, et al. [137] also developed a tutoring system targeting sight word instruction by combining VR technology and social robotics. This system featured a small-group classroom environment with a virtual agent as the teacher, and a humanoid robot as the peer, to facilitate observational learning, i.e., learning by watching others and imitating [138]. The effectiveness of the tutoring system was evaluated through an intervention study involving three participants with ASD who acquired, maintained, and generalized all the words that had been explicitly taught to them by the system and made fewer errors on the words that were also taught to their robot peer. 
Nubia, et al. [139] resorted to AR to design and develop a mobile application that could serve as an alternative tool for semantic therapies to help improve semantic word knowledge in children with ASD. This application could stimulate oral and expressive language production in children with ASD by playing onomatopoeias or the sounds associated with animals and objects. Compared with the conventional therapy, intervention using the AR mobile application led to an increase, which was confirmed by speech therapists, in the verbal language produced by the ASD participants [139].

Apart from vocabulary, grammar, and semantics, the positive impacts of virtual elements and techniques on speech and language training in ASD have also been extended to the domain of pronunciation. Chen, et al. [140], incorporating the ideas of imitative learning [141], designed a 3-D virtual imitation intervention system to provide audiovisual pronunciation training for children with ASD. The computer-assisted 3-D virtual pronunciation tutor was able to present, in a multimodal and real-data-driven manner, the places and manners of Mandarin phoneme articulation and has been proved to efficiently enhance the accuracy of Mandarin consonant and vowel pronunciation in low-functioning children with ASD [140].

\section{Limitations and Disputes}

While the application of VR to ASD research and intervention holds significant potential and considerable achievements have been recorded in terms of improving ASD individuals' social communication abilities, there are technology- and design-related limitations that remain to be addressed as well as controversial issues that must be taken into consideration in the design of future studies.

\subsection{Limitations in Technology and Design}

Though VR technology has improved tremendously in recent years, certain technical imperfections still exist such as graphic update rate, field of view (for HMDs), lags between head tracking and visualization [142,143]. Besides these limitations, a particular technical challenge for VR applications is the simulation of behaviorally realistic virtual avatars. Current VR technology has been capable of creating vivid and lifelike avatars but they are inevitably different from real humans in either appearance or behavior. This would to some extent influence the responses of participants [144] in that if they are constantly reminded that the people they encounter are not real by the not-authentic-enough behaviors of avatars, the way they behave and respond in virtual worlds would diverge from that in the real world and could thus not be used as the indicator of their abilities. For example, in the study conducted by Parsons et al., one participant reported that he did not walk across the grass of a garden in the VE because that could make his shoes muddy; however, he walked between two people having a conversation in the cafeteria because they "weren't real" and "it didn't matter" [145]. Another technological limitation is the restricted range (usually a few square meters) within which participants have to use the interaction and tracking devices in order to maintain good connection and interaction with the VE. These technical restrictions might limit the level of immersion provided by a VR system and result in a lower experience of presence [146].

In addition to the above technical limitations, inadequacies exist regarding learning content and activity design. Despite the promising results of current successful attempts in VR-based training in ASD, the VR learning content used in many existing studies focused on too confined scenarios and situations [147] and the skills being taught were often procedural and strongly rule-based, with inadequate emphasis laid on the skills required in relatively unpredictable social situations [9]. Another problem with the content and design is that a certain number of training activities in current VR intervention are illdevised, including only repeated and tedium practice that is likely to bore ASD children after the initial novelty wears off. One possible solution to this issue is to add recreation value to the VR training systems by borrowing serious game design concepts [148] from the entertainment sector. More enjoyable content and increasingly engaging activities 
would also attract more participants to the training systems, which can prevent the drawback of inadequate statistical power caused by the small number of participants in most previous feasibility and validity studies [149], helping researchers draw more convincing conclusions on the effectiveness of VR-based intervention systems.

\subsection{Current Disputes}

The disputes over the application of VR technology to ASD research and therapy cover mainly three aspects, i.e., challenges to the veridicality assumption, safety concerns, and ethical considerations. Some researchers have queried the authenticity and veridicality of VEs that have provided a strong argument for the integration of VR-based design into various educational and health fields [144]. The potential and strengths of using VR to investigate social communication and interactions are grounded on the fundamental belief that VEs provide realistic and authentic experiences that mirror real-world behaviors and responses. However, this assumption may be open to question because the degree of perceived realism in VEs can be affected by many factors including the features of VEs (e.g., the degree of autonomy allowed in the VEs, how real the avatars and the scenarios are [150], the way of interaction between users and systems [151], whether the avatars are controlled by humans or computers [152]) and the background characteristics of users (e.g., whether users have postural instability, whether they are susceptible to motion sickness [153]). The VR technologies adopted by many existing studies, such as AR and desktop VR, are actually non-immersive and provide rather limited autonomy. Although they have taken a step further compared to the traditional simple and static stimuli, it is still debatable to what extent the responses recorded in these VEs are generalizable to realworld responding and interpretation [144].

Moreover, even for the highly immersive VEs created by HMDs or CAVE-like systems, which are among the most advanced VR techniques so far, technological limitations that would influence the perceived realism of VR experience and the transfer of learning to real-world contexts still exist, which leaves plenty of room and possibilities for future improvement. For example, Parsons [144] suggested that there are at least two disparate directions for future efforts to move the field forward, i.e., to increase the realism of VEs and pursue extreme veridicality of VR technology or to diverge from the pursuit of pure veridicality and consider more the needs and preferences of the users. Within the scope of ASD research and intervention, the latter perspective would lay more emphasis on questions including the following. For people with ASD and their families, what elements in VEs are the most important and would be particularly useful to support and enhance their communication and learning? Do the degree of realism and the veridicality linearly correlate with the effectiveness of VR-based ASD training systems or is there a breakpoint at which the effectiveness plateaus? If the breakpoint exists, what degree of authenticity is optimal so that people with ASD and their families could benefit the most from VR technology without spending too much time and effort seeking cutting-edge equipment or waiting for further technology development. There is a need to inquire into these aspects directly and in more detail in order to really understand how VR technology can positively influence the ASD population's learning, well-being, and life quality.

Safety risks, both physically and psychologically, might be associated with the use of VR. A common physical safety concern associated with VR experience is cybersickness, which can cause fatigue, malaise, and dizziness, or even elicit a series of symptoms such as eye strain, nausea, and bodily disorientation [154,155]. In addition to the possible physical discomfort, some researchers pointed out the potential psychological safety risks accompanying but not unique to the use of VR, suggesting that similar to the problems documented in people engaging in excessive use of video games, extended and continuous use of VR might be linked with certain mental uneasiness [156]. These safety risks do have led to some disputes over the use of VR in the ASD population, but rather than discouraging its application, we could instead carefully consider and control these risks in the design of future studies. For example, to minimize the consequences of cybersickness 
(including symptoms of nausea, vomiting, drowsiness, headache, loss of balance and problematic eye-hand coordination), risk assessment based on predictive questionnaires such as the Motion Sickness Susceptibility Questionnaire (MSSQ-Short) [157] ought to be conducted prior to training or experiments and immediate reports of discomfort as well as timely support from therapists are necessary during the initial use of VR. For ASD trainees who have no previous exposure to VR, transition periods could be arranged to help them gradually adapt to VEs. As for the concern about psychological safety, the duration of exposure to VR should be strictly controlled in both research and therapy sessions to prevent the negative impact of excessive and inappropriate use from overshadowing the benefits of this technology.

Apart from the challenges to veridicality and the safety concerns associated with VR, ethical considerations also provoke extensive discussion, among which the most debated one might be the question of privacy and confidentiality during data collection [156]. In the process of VR-enabled research and intervention, eye-movement patterns, facial expressions, and body responses and reflexes, which constitute one's distinct "kinematic fingerprint" [155], would be recorded. Given the commercial nature of many VR products, this personal information of participants could be accessed by the companies that deliver the VR software who tend to state in the privacy policy that user data may be collected. Therefore, researchers and therapists using VR technologies need to provide participants clearly-stated informed consent forms to ensure that they are aware of and consent to the data collection issue before participation.

\section{Future Directions}

Since the first employment of VR technologies on the ASD population in the 1990s [48], there has been a significant increase over the past decades in the number of studies using VR for ASD research and intervention [158]. The literature has seen increasing recognition of the benefits and potentials of VR to facilitate learning, especially in social environments in individuals with autism. But there is still much work that remains to be done in this research area. Future efforts can be directed towards application expansion and improvement, technology enhancement, and brain-based research and theoretical model development. The contributions of these basic and applied studies would be at least three-fold: benefiting the ASD population, reducing the workload of therapists, and facilitating the advancement of the VR technology as well as theoretical modeling of VR application with beneficial social and cultural consequences.

\subsection{Application Expansion and Improvement}

Existing VR-based training systems and platforms have paid much attention to improving ASD individuals' performance in social functioning, emotion processing, and speech and language, but a majority of them treated these socially important aspects independently and designed training programs that centered around one specific respect; few have taken an integrated view of these skills to systematically enhance social communication in ASD. Within each aspect, the research was also discrete and divided. For example, the VR-based intervention programs and systems for speech and language training have focused on grammar and vocabulary, or semantics, or pronunciation, but rarely attempted to integrate these components of language communication skills in one training system. Many training programs, though proved to be effective in improving ASD trainees' specific skills, often meet with limited success in enhancing the overall social performance of the ASD population [159-161]. One probable explanation for this problem is that intervention and training that involves correlates of different target skill domains is often missing from the research and treatment efforts in ASD, and even though these correlates are included in some programs, they are not always trained systematically [160]. The "transactive" relationships between different behavioral domains [162] determine that improvements in one domain contribute to progress in other domains and delay in any one could affect development in the others [163,164]. For example, VR training programs 
aiming to improve employment-related skills in ASD may lead to better use of strategies by participants with ASD during job seeking, but their actual overall performance might improve little due to the remaining weakness in emotion perception or speech production and understanding [115]. Effective intervention in social communication in ASD thus not only requires training in specific social aspects including social functioning, emotion processing, and speech and language, but also calls for integrative efforts to resolve the difficulties that correlate these domains.

To systematically improve social communication performance that involves various social domains, future VR-based ASD intervention systems can lay more emphasis on the training and learning of prosody, which plays a vital role in a range of communicative functions (linguistic/grammatical, pragmatic, affective, etc.) [165] and the correct use of which, promoting peer interaction and socialization, is fundamental for both personal development and social integration of individuals with ASD [166]. Prosody functions at three major levels (not mutually exclusive) to enable smooth social communication: grammatical prosody is crucial for the expression of semantic meaning (e.g., resolving semantic ambiguity); pragmatic prosody conveys the speaker's intentions (e.g., emphasizing certain information); affective prosody implies the speaker's emotions or affective states (e.g., feeling happy or sad, relaxed or anxious) [167]. These functions cover a wide range of both linguistic and socio-affective domains, which means that atypical use and understanding of prosody would greatly undermine efficient social interaction and language communication. More research and intervention studies are thus recommended to combine VR technology with integrated training in prosody, both linguistic and affective, and its combination with grammar, semantics and pragmatics to improve socio-affective and linguistic skills and ultimately enhance overall social communication in ASD.

Since a large proportion of ASD individuals are in childhood or of school age, ideas in the field of education would be helpful for alleviating ASD core symptoms over the course of development. Existing research on VR-based ASD training has benefited much from pedagogical theories [137] and future exploration could continue integrating philosophy in education and learning to develop better VR-based training programs for ASD. For example, Iovannone, et al. [168] proposed six essential components to be included in an effective educational program for ASD students, i.e., individualized supports and services for students and families, specialized curriculum content, systematic instruction, comprehensible and/or structured environments, a functional approach to problem behaviors, and family involvement. These components, especially the first two, could be well-incorporated into VR-driven training programs by providing language- and culturalspecific individualized training packages to enable more effective targeted intervention.

Future design of VR training systems, especially for social communication training, needs to show more consideration for users' language and cultural backgrounds. For example, it has been hypothesized that prosodic deficits in the ASD population reside primarily in the pragmatic and affective aspects, with grammatical aspects relatively spared [167]. However, this conclusion was drawn mainly based on data collected from ASD individuals speaking English or other non-tonal languages where syllable-level prosodic variations (or lexical tones) do not distinguish lexical meaning. For tonal language speakers with autism, atypical perception of lexical tones has been observed [169], which indicates impairment in grammatical-prosodic processing in addition to their pragmatic difficulties [170]. Therefore, whether grammatical functions of prosody are impaired among the ASD population is disputed and is likely to differ due to the influence of language backgrounds, so the design of future VR-based practice should take into consideration this language-specific problem and be tailored to ASD individuals according to their language backgrounds. Similarly, cultural factors should also be taken into account in future exploration in this area as many social behaviors are culture-dependent. For instance, training on the social skills of people with ASD usually encourages them to make eye contact with the communication partner. However, looking the elders directly in the eye is regarded as disrespectful in some countries such as India and Bangladesh [171]. It is 
thus crucial to design the training scenarios and activities with an eye to the cultural backgrounds of the ASD users.

The heterogeneity within the autism spectrum implies that even if with the same language and cultural background, each individual with ASD is still unique and a specific intervention or treatment may not always be the best for the whole population [172]. The effectiveness of the intervention depends largely on how accurately it targets the specific vulnerabilities of the ASD participant, so it is necessary to offer individualized VR-based training and intervention that is able to cater for the preferences of each ASD individual. In conventional intervention, therapists tend to adjust the intervention paradigm according to the ASD individual's specific cognitive and behavioral conditions [97]. Future development of VR-based training systems for ASD should also take into consideration the adaptation of skill training to the user's specific needs. For example, research on emotion processing in ASD has produced very mixed results, with disagreement persisting over whether it is impaired in ASD individuals [54]. The heterogeneous performance across tasks and across individuals (even in one single study) suggests that emotion processing may not be universally impaired in ASD and the degree of deficits may also vary across individuals [173]. VR-based training systems could then incorporate AI assessment procedures to automatically examine the degree of certain deficits in the specific user and adjust the subsequent training plan according to the assessment results. For instance, for users with ASD who are assessed to have particular difficulty perceiving and understanding certain emotions, the VR training system may correspondingly adjust the proportion of training in emotion processing and provide targeted practice to promote optimum learning of relevant social skills.

For the same person, the condition may also change over time. In the short term, the performance during one intervention session would fluctuate and calls for dynamic and real-time adaptation. In the long term, the variation in the different stages of development also requires the intervention objectives and strategies to be tuned accordingly. For example, school-aged autistic children may need more instruction in coping with bullying whereas young adults with ASD would desire extra training in employment skills such as finding and keeping a job. Besides the change in intervention-related needs, the cognitive level and the language ability of the ASD user might also improve over the course of development $[174,175]$. Then, in order for the intervention to be continuously effective, the learning content, the language material and the activity design in the VR training systems should be able to be updated along with the developmental change of the ASD user.

\subsection{Technology Enhancement}

As illustrated in the previous section, there is much room for future improvements to VR-driven training systems for ASD. Potential breakthroughs in all these directions require corresponding enhancement of VR technology to facilitate the application expansion. For example, researchers and engineers on VR technology development can investigate how to combine VR technologies with AI and machine-learning techniques to promote customized intervention and provide tailored support. Automatic recognition and assessment technology including automatic speech recognition and evaluation [176,177], automatic assessment of cognitive and emotional states [178] need to be embedded into the VR training systems to measure and track users' abilities and states and deliver immediate and timely feedback prior to, during, and after training. The incorporation of accurate, intelligent, and efficient automatic evaluation techniques can greatly ease the workload of speech-language and cognitive-behavioral therapists and more importantly, offer much-needed assessment and intervention services for the ASD population living in less developed regions that lack trained and qualified therapists.

Future exploration may expand the functionality of VR so that it can be part of big data that promote worldwide collaboration on autism research and facilitate data-driven discoveries. The ideal big data for autism research should be both "broad" and "deep". Broad data is characteristic of large sample sizes whereas deep data involve analysis of 
multiple levels of information collected on the same individuals including behavior and development, neural systems, and outcomes of clinical treatment [179]. VR training platforms can be a perfect channel for gathering such "broad" and "deep" big data owing to their capability to collect dynamic and detailed behavioral and neural data at various stages of training and intervention. Future VR training systems can be improved to not only enable recording of the multi-level data of ASD trainees who have given informed consent, but also allow uploading of these data onto cloud storage space as well as later downloading of them by authorized users. Furthermore, researchers can draw from techniques and strategies that are commonly employed in designing, building, and managing a database and work out efficient ways of VR data pooling and collating to develop secure and searchable VR-based multi-level ASD data repositories for research purposes. Such databases can be very helpful in providing comparison and reference for ASD assessment and diagnosis as well as furthering our understanding of heterogeneity in autism [179].

Another direction of function expansion for future VR-based ASD training systems is to provide ASD individuals and therapists with personal data banks for monitoring progress and informing subsequent intervention decisions. The training systems can be enhanced to regularly create and push visualized personal reports that document the ASD user's progress and status quo; for example, how much the ASD trainee has progressed in certain skills since the last time, what are the skills he or she has improved the most, which aspects require increasing practice in later training. This kind of feedback would be encouraging for ASD individuals and their families by assuring them that conditions are indeed improving and they should persevere with the training. A more detailed personal data bank would also be useful for therapists as information on the pretreatment characteristics is often needed for them to individualize the following intervention plan [97].

\subsection{Brain-based Research and Theoretical Model Development}

Existing evaluation of the treatment effectiveness of VR-based training in ASD relies primarily on behaviors such as improved performance on tasks or tests, with limited evidence for the neural changes underlying these behavioral gains. Although a few pioneering studies have attempted to examine how therapeutic responses to VR training reflect brain changes in ASD [116], it remains to be answered whether VR can support the development of brain networks of ASD individuals. Brain-based research is crucial for VR application to ASD because brain data is an indispensable level of "deep" big data [179] and plays a crucial role in the substantiation, revision and updating of theoretical models in ASD research [180]. Future investigation on VR integration into ASD assessment and intervention is thus recommended to utilize neurophysiological and neuroimaging techniques to track and measure brain responses of ASD participants before, during, and after VR training to evaluate the efficacy and limitations of multi-modal VR-based training from the perspective of brain plasticity and to elucidate the neural underpinnings of behavioral improvements both at the group level and the individual level.

Data obtained from brain-based research is also useful for theoretical modeling of VR technology and application. Existing theoretical models of VR technology in ASD mostly focus on multiple levels of cognitive and behavioral enhancement [8] and few of them have touched upon how the brain or neural mechanisms of ASD individuals would evolve due to the exposure to VR training. Future efforts could extend the existing models by linking brain activities and changes with behavioral improvements at multiple levels or developing new models that expound the influence of VR training on brain changes in ASD individuals at different developmental stages. In particular, specific concepts and issues such as the understanding of self vs. other and the multi-channel and multimodal nature of social signal processing that can inform the biological, psychological and neurophysiological underpinnings of social communication need to be clarified. Such social neuroscience models incorporating both behavioral and neural aspects will provide insightful guidance for the designing, developing and evaluating of VR-based ASD training 
platforms that can be potentially added to traditional behavioral therapies and educational settings with great social and cultural consequences.

Author Contributions: Conceptualization, Y.Z.; writing-original draft preparation, M.Z.; writing - review and editing, H.D. and Y.Z. All authors have read and agreed to the published version of the manuscript.

Funding: This work was supported by grants from the Major Project of National Social Science Foundation of China (18ZDA293).

Institutional Review Board Statement: Not applicable.

Informed Consent Statement: Not applicable.

Data Availability Statement: Not applicable.

Conflicts of Interest: The authors declare no conflict of interest.

\section{References}

1. American Psychiatric Association. Diagnostic and statistical manual of mental disorders (5th ed.); American Psychiatric Publishing: 2013.

2. Howlin, P. Autism: Preparing for adulthood; Routledge: London, 1997.

3. Bekele, E.; Zheng, Z.; Swanson, A.; Crittendon, J.; Warren, Z.; Sarkar, N. Understanding how adolescents with autism respond to facial expressions in virtual reality environments. IEEE Transactions on Visualization and Computer Graphics 2013, 19, 711-720, doi:10.1109/TVCG.2013.42.

4. Orlosky, J.; Itoh, Y.; Ranchet, M.; Kiyokawa, K.; Morgan, J.; Devos, H. Emulation of physician tasks in eye-tracked virtual reality for remote diagnosis of neurodegenerative disease. IEEE Transactions on Visualization and Computer Graphics 2017, 23, 1302-1311, doi:10.1109/TVCG.2017.2657018.

5. Bird, M.-L.; Cannell, J.; Jovic, E.; Rathjen, A.; Lane, K.; Tyson, A.; Callisaya, M.; Smith, S. A randomized controlled trial investigating the efficacy of virtual reality in inpatient stroke rehabilitation. Arch. Phys. Med. Rehabil. 2017, 98, e27, doi:10.1016/j.apmr.2017.08.084.

6. Pulijala, Y.; Ma, M.; Pears, M.; Peebles, D.; Ayoub, A. Effectiveness of immersive virtual reality in surgical training-a randomized control trial. Journal of Oral and Maxillofacial Surgery 2018, 76, 1065-1072, doi:10.1016/j.joms.2017.10.002.

7. Mishkind, M.C.; Norr, A.M.; Katz, A.C.; Reger, G.M. Review of virtual reality treatment in psychiatry: Evidence versus current diffusion and use. Current Psychiatry Reports 2017, 19, 80, doi:10.1007/s11920-017-0836-0.

8. Dhamodharan, T.; Thomas, M.; Ramdoss, S.; JothiKumar, K.; SaravanaSundharam, S.; Muthuramalingam, B.; Hussainalikhan, N.; Ravichandran, S.; Vadivel, V.; Suresh, P. Cognitive rehabilitation for autism children mental status observation using virtual reality based interactive environment. In Proceedings of the International Conference on Intelligent Human Systems Integration, Modena, Italy, 19-21 February, 2020; pp. 1213-1218.

9. Parsons, S.; Cobb, S. State-of-the-art of virtual reality technologies for children on the autism spectrum. European Journal of Special Needs Education 2011, 26, 355-366, doi:10.1080/08856257.2011.593831.

10. Mosher, M.A.; Carreon, A.C. Teaching social skills to students with autism spectrum disorder through augmented, virtual and mixed reality. Research in Learning Technology 2021, 29, doi:10.25304/rlt.v29.2626.

11. Dechsling, A.; Shic, F.; Zhang, D.; Marschik, P.B.; Esposito, G.; Orm, S.; Sütterlin, S.; Kalandadze, T.; Øien, R.A.; Nordahl-Hansen, A. Virtual reality and naturalistic developmental behavioral interventions for children with autism spectrum disorder. Res. Dev. Disabil. 2021, 111, 103885, doi:10.1016/j.ridd.2021.103885.

12. Wilson, B.A. Cognitive rehabilitation: How it is and how it might be. J. Int. Neuropsychol. Soc. 1997, 3, 487-496, doi:10.1017/S1355617797004876.

13. Clare, L.; Wilson, B.A.; Carter, G.; Hodges, J.R. Cognitive rehabilitation as a component of early intervention in alzheimer's disease: A single case study. Aging Ment. Health 2003, 7, 15-21, doi:10.1080/1360786021000045854.

14. Cipriani, G.; Bianchetti, A.; Trabucchi, M. Outcomes of a computer-based cognitive rehabilitation program on alzheimer's disease patients compared with those on patients affected by mild cognitive impairment. Arch. Gerontol. Geriatr. 2006, 43, 327335, doi:10.1016/j.archger.2005.12.003.

15. Seelye, A.M.; Schmitter-Edgecombe, M.; Das, B.; Cook, D.J. Application of cognitive rehabilitation theory to the development of smart prompting technologies. IEEE Rev. Biomed. Eng. 2012, 5, 29-44, doi:10.1109/RBME.2012.2196691.

16. Chen, C.J. Theoretical bases for using virtual reality in education. Themes in Science and Technology Education 2010, 2, 71-90.

17. Hedberg, J.; Alexander, S. Virtual reality in education: Defining researchable issues. Educational Media International 1994, 31, 214220, doi:10.1080/0952398940310402.

18. Kearsley, G.; Shneiderman, B. Engagement theory: A framework for technology-based teaching and learning. Educational Technology 1998, 38, 20-23.

19. Kolb, D.A. Experiential learning: Experience as the source of learning and development; FT Press: 2014. 
20. Kalyuga, S. Enhancing instructional efficiency of interactive e-learning environments: A cognitive load perspective. Educ. Psychol. Rev. 2007, 19, 387-399, doi:10.1007/s10648-007-9051-6.

21. Wang, X.; Laffey, J.; Xing, W.; Galyen, K.; Stichter, J. Fostering verbal and non-verbal social interactions in a 3D collaborative virtual learning environment: A case study of youth with autism spectrum disorders learning social competence in isocial. Educational Technology Research and Development 2017, 65, 1015-1039, doi:10.1007/s11423-017-9512-7.

22. McCleery, J.P.; Zitter, A.; Solórzano, R.; Turnacioglu, S.; Miller, J.S.; Ravindran, V.; Parish-Morris, J. Safety and feasibility of an immersive virtual reality intervention program for teaching police interaction skills to adolescents and adults with autism. Autism Res. 2020, 13, 1418-1424, doi:10.1002/aur.2352.

23. Schmidt, M.; Glaser, N. Investigating the usability and learner experience of a virtual reality adaptive skills intervention for adults with autism spectrum disorder. Educational Technology Research and Development 2021, 69, 1665-1699, doi:10.1007/s11423021-10005-8.

24. Miller, I.T.; Wiederhold, B.K.; Miller, C.S.; Wiederhold, M.D. Virtual reality air travel training with children on the autism spectrum: A preliminary report. Cyberpsychology, Behavior, and Social Networking 2020, 23, 10-15, doi:10.1089/cyber.2019.0093.

25. Schneider, S.; Beege, M.; Nebel, S.; Schnaubert, L.; Rey, G.D. The cognitive-affective-social theory of learning in digital environments (CASTLE). Educ. Psychol. Rev. 2021, 1-38, doi:10.1007/s10648-021-09626-5.

26. Kort, B.; Reilly, R.; Picard, R.W. An affective model of interplay between emotions and learning: Reengineering educational pedagogy-building a learning companion. In Proceedings of the IEEE International Conference on Advanced Learning Technologies, Madison, WI, USA, 6-8 Aug., 2001; pp. 43-46.

27. Ip, H.H.-S.; Byrne, J.; Cheng, S.-H.; Kwok, R.C.-W. The samal model for affective learning. In 17th international conference on distributed multimedia systems, DMS 2011; Knowledge Systems Institute Graduate School: 2011; pp. $216-221$.

28. Kwok, R.C.-W.; Cheng, S.H.; Ip, H.H.-S.; Kong, J.S.-L. Design of affectively evocative smart ambient media for learning. In Proceedings of the 2009 Workshop on Ambient Media Computing, Beijing, China, 2009; pp. 65-76.

29. Bambury, S. The depths of VR model v2.0. Available online: https://www.virtualiteach.com/post/the-depths-of-vr-model-v2-0 (accessed on 13 April 2021).

30. Gigante, M.A. Virtual reality: Definitions, history and applications. In Virtual reality systems, Earnshaw, R.A., Gigante, M.A., Jones, H., Eds.; Academic Press: Boston, 1993; pp. 3-14.

31. Stewart Rosenfield, N.; Lamkin, K.; Re, J.; Day, K.; Boyd, L.; Linstead, E. A virtual reality system for practicing conversation skills for children with autism. Multimodal Technologies and Interaction 2019, 3, doi:10.3390/mti3020028.

32. Mesa-Gresa, P.; Gil-Gómez, H.; Lozano-Quilis, J.A.; Gil-Gómez, J.A. Effectiveness of virtual reality for children and adolescents with autism spectrum disorder: An evidence-based systematic review. Sensors 2018, 18, 2486, doi:10.3390/s18082486.

33. Eskes, G.A.; Bryson, S.E.; McCormick, T.A. Comprehension of concrete and abstract words in autistic children. J. Autism Dev. Disord. 1990, 20, 61-73.

34. Cromby, J.; Standen, P.J.; Brown, D.J. The potentials of virtual environments in the education and training of people with learning disabilities. Journal of Intellectual Disability Research 1996, 40, 489-501.

35. Samson, A.C.; Phillips, J.M.; Parker, K.J.; Shah, S.; Gross, J.J.; Hardan, A.Y. Emotion dysregulation and the core features of autism spectrum disorder. J. Autism Dev. Disord. 2014, 44, 1766-1772, doi:10.1007/s10803-013-2022-5.

36. Trevarthen, C.; Delafield-Butt, J.T. Autism as a developmental disorder in intentional movement and affective engagement. Front. Integr. Neurosci. 2013, 7, 49, doi:10.3389/fnint.2013.00049.

37. Bradley, R.; Newbutt, N. Autism and virtual reality head-mounted displays: A state of the art systematic review. Journal of Enabling Technologies 2018, 12, 101-113, doi:10.1108/JET-01-2018-0004.

38. Browning, D.R.; Cruz-Neira, C.; Sandin, D.J.; DeFanti, T.A. The CAVE automatic virtual environment: Projection-based virtual environments and disability. In Proceedings of the The First Annual International Conference, Virtual Reality and People with Disabilities, San Francisco, CA, USA, 1st June, 1993.

39. Li, C.; Ip, H.H.S.; Ma, P.K. A design framework of virtual reality enabled experiential learning for children with autism spectrum disorder. In Proceedings of the International Conference on Blended Learning, Hradec Kralove, Czech Republic, 2-4 July, 2019; pp. 93-102.

40. Cruz-Neira, C.; Sandin, D.J.; DeFanti, T.A. Surround-screen projection-based virtual reality: The design and implementation of the CAVE. In Proceedings of the 20th Annual Conference on Computer Graphics and Interactive Techniques, Anaheim, CA, USA, 2-6 August, 1993; pp. 135-142.

41. Ip, H.H.S.; Li, C. Virtual reality-based learning environments: Recent developments and ongoing challenges. In Proceedings of the Hybrid Learning: Innovation in Educational Practices, Cham, 2015; pp. 3-14.

42. Alizadeh, M. Virtual reality in the language classroom: Theory and practice. CALL-EJ (Computer Assisted Language Learning Electronic Journal) 2019, 20, 21-30.

43. Gigante, M.A. Virtual reality: Enabling technologies. In Virtual reality systems, Earnshaw, R.A., Gigante, M.A., Jones, H., Eds.; Academic Press: Boston, 1993; pp. 15-25.

44. Kandalaft, M.R.; Didehbani, N.; Krawczyk, D.C.; Allen, T.T.; Chapman, S.B. Virtual reality social cognition training for young adults with high-functioning autism. J. Autism Dev. Disord. 2013, 43, 34-44, doi:10.1007/s10803-012-1544-6.

45. Doniger, G.M.; Beeri, M.S.; Bahar-Fuchs, A.; Gottlieb, A.; Tkachov, A.; Kenan, H.; Livny, A.; Bahat, Y.; Sharon, H.; Ben-Gal, O.; et al. Virtual reality-based cognitive-motor training for middle-aged adults at high alzheimer's disease risk: A randomized controlled trial. Alzheimer's \& Dementia: Translational Research \& Clinical Interventions 2018, 4, 118-129, doi:https://doi.org/10.1016/j.trci.2018.02.005. 
46. Bouchard, S.; Dumoulin, S.; Robillard, G.; Guitard, T.; Klinger, É.; Forget, H.; Loranger, C.; Roucaut, F.X. Virtual reality compared with in vivo exposure in the treatment of social anxiety disorder: A three-arm randomised controlled trial. Br. J. Psychiatry 2017, 210, 276-283, doi:10.1192/bjp.bp.116.184234.

47. Rus-Calafell, M.; Gutiérrez-Maldonado, J.; Ribas-Sabaté, J. A virtual reality-integrated program for improving social skills in patients with schizophrenia: A pilot study. J. Behav. Ther. Exp. Psychiatry 2014, 45, 81-89, doi:10.1016/j.jbtep.2013.09.002.

48. Strickland, D.; Marcus, L.M.; Mesibov, G.B.; Hogan, K. Brief report: Two case studies using virtual reality as a learning tool for autistic children. J. Autism Dev. Disord. 1996, 26, 651-659, doi:10.1007/BF02172354.

49. Li, C.; Yuan, S.; Ip, H. A case study on delivering virtual reality learning for children with autism spectrum disorder using virtual reality headsets. In Proceedings of the 10th International Conference on Education and New Learning Technologies (EDULEARN18), Palma de Mallorca, Spain, 2-4 July, 2018; pp. 728-734.

50. Newbutt, N.; Bradley, R.; Conley, I. Using virtual reality head-mounted displays in schools with autistic children: Views, experiences, and future directions. Cyberpsychology, Behavior, and Social Networking 2019, 23, 23-33, doi:10.1089/cyber.2019.0206.

51. Newbutt, N.; Sung, C.; Kuo, H.-J.; Leahy, M.J.; Lin, C.-C.; Tong, B. Brief report: A pilot study of the use of a virtual reality headset in autism populations. J. Autism Dev. Disord. 2016, 46, 3166-3176, doi:10.1007/s10803-016-2830-5.

52. Sigman, M.; Dijamco, A.; Gratier, M.; Rozga, A. Early detection of core deficits in autism. Mental Retardation and Developmental Disabilities Research Reviews 2004, 10, 221-233, doi:10.1002/mrdd.20046.

53. Hale, C.M.; Tager-Flusberg, H. Social communication in children with autism: The relationship between theory of mind and discourse development. Autism 2005, 9, 157-178, doi:10.1177/1362361305051395.

54. Uljarevic, M.; Hamilton, A. Recognition of emotions in autism: A formal meta-analysis. J. Autism Dev. Disord. 2013, 43, 15171526, doi:10.1007/s10803-012-1695-5.

55. Zhang, M.; Xu, S.; Chen, Y.; Lin, Y.; Ding, H.; Zhang, Y. Recognition of affective prosody in autism spectrum conditions: A systematic review and meta-analysis. Autism 2021, doi:10.1177/1362361321995725.

56. Lahiri, U.; Warren, Z.; Sarkar, N. Design of a gaze-sensitive virtual social interactive system for children with autism. IEEE Transactions on Neural Systems and Rehabilitation Engineering 2011, 19, 443-452, doi:10.1109/TNSRE.2011.2153874.

57. Sigman, M.; Mundy, P.; Sherman, T.; Ungerer, J. Social interactions of autistic, mentally retarded and normal children and their caregivers. Journal of Child Psychology and Psychiatry 1986, 27, 647-656, doi:10.1111/j.1469-7610.1986.tb00189.x.

58. Nadig, A.; Shaw, H. Acoustic and perceptual measurement of expressive prosody in high-functioning autism: Increased pitch range and what it means to listeners. J. Autism Dev. Disord. 2012, 42, 499-511, doi:10.1007/s10803-011-1264-3.

59. Paul, R.; Bianchi, N.; Augustyn, A.; Klin, A.; Volkmar, F.R. Production of syllable stress in speakers with autism spectrum disorders. Res. Autism Spectr. Disord. 2008, 2, 110-124, doi:10.1016/j.rasd.2007.04.001.

60. Tager-Flusberg, H.; Anderson, M. The development of contingent discourse ability in autistic children. Journal of Child Psychology and Psychiatry 1991, 32, 1123-1134, doi:10.1111/j.1469-7610.1991.tb00353.x.

61. Tager-Flusberg, H. Dissociations in form and function in the acquisition of language by autistic children. In Constraints on language acquisition: Studies of atypical children, Tager-Flusberg, H., Ed.; Erlbaum: Hillsdale, NJ, 1994.

62. Hale, C.M.; Tager-Flusberg, H. Brief report: The relationship between discourse deficits and autism symptomatology. J. Autism Dev. Disord. 2005, 35, 519-524, doi:10.1007/s10803-005-5065-4.

63. Heerey, E.A.; Keltner, D.; Capps, L.M. Making sense of self-conscious emotion: Linking theory of mind and emotion in children with autism. Emotion 2003, 3, 394-400, doi:10.1037/1528-3542.3.4.394.

64. Baron-Cohen, S.; Tager-Flusberg, H.; Cohen, D.J., (Eds.) Understanding other minds: Perspectives from autism. Oxford University Press: New York, NY, 1994.

65. Baron-Cohen, S.; Tager-Flusberg, H.; Cohen, D.J., (Eds.) Understanding other minds: Perspectives from developmental cognitive neuroscience, 2nd ed. 2 ed.; Oxford University Press: New York, NY, 2000.

66. Tager-Flusberg, H.; Paul, R.; Lord, C. Language and communication in autism. In Handbook of autism and pervasive developmental disorders: Diagnosis, development, neurobiology, and behavior, vol. 1, 3rd ed.; John Wiley \& Sons Inc: Hoboken, NJ, US, 2005; pp. 335364.

67. Baio, J.; Wiggins, L.; Christensen, D.L.; Maenner, M.J.; Daniels, J.; Warren, Z.; Kurzius-Spencer, M.; Zahorodny, W.; Robinson Rosenberg, C.; White, T.; et al. Prevalence of autism spectrum disorder among children aged 8 years - autism and developmental disabilities monitoring network, 11 sites, United States, 2014. Morbidity and Mortality Weekly Report. Surveillance Summaries (Washington, D.C.: 2002) 2018, 67, 1-23, doi:10.15585/mmwr.ss6706a1.

68. Sun, X.; Allison, C.; Wei, L.; Matthews, F.E.; Auyeung, B.; Wu, Y.Y.; Griffiths, S.; Zhang, J.; Baron-Cohen, S.; Brayne, C. Autism prevalence in china is comparable to western prevalence. Mol. Autism 2019, 10, 7, doi:10.1186/s13229-018-0246-0.

69. Kim, Y.S.; Leventhal, B.L.; Koh, Y.-J.; Fombonne, E.; Laska, E.; Lim, E.-C.; Cheon, K.-A.; Kim, S.-J.; Kim, Y.-K.; Lee, H.; et al. Prevalence of autism spectrum disorders in a total population sample. Am. J. Psychiatry 2011, 168, 904-912, doi:10.1176/appi.ajp.2011.10101532.

70. Lai, D.-C.; Tseng, Y.-C.; Hou, Y.-M.; Guo, H.-R. Gender and geographic differences in the prevalence of autism spectrum disorders in children: Analysis of data from the national disability registry of taiwan. Res. Dev. Disabil. 2012, 33, 909-915, doi:10.1016/j.ridd.2011.12.015.

71. Matson, J.L.; Kozlowski, A.M. The increasing prevalence of autism spectrum disorders. Res. Autism Spectr. Disord. 2011, 5, 418425, doi:10.1016/j.rasd.2010.06.004.

72. Nevison, C.; Blaxill, M.; Zahorodny, W. California autism prevalence trends from 1931 to 2014 and comparison to national ASD data from idea and addm. J. Autism Dev. Disord. 2018, 48, 4103-4117, doi:10.1007/s10803-018-3670-2. 
73. Lavelle, T.A.; Weinstein, M.C.; Newhouse, J.P.; Munir, K.; Kuhlthau, K.A.; Prosser, L.A. Economic burden of childhood autism spectrum disorders. Pediatrics 2014, 133, e520, doi:10.1542/peds.2013-0763.

74. Ghaziuddin, M. Asperger syndrome: Associated psychiatric and medical conditions. Focus Autism Other Dev. Disabl. 2002, 17, 138-144, doi:10.1177/10883576020170030301.

75. White, S.W.; Oswald, D.; Ollendick, T.; Scahill, L. Anxiety in children and adolescents with autism spectrum disorders. Clin. Psychol. Rev. 2009, 29, 216-229, doi:10.1016/j.cpr.2009.01.003.

76. Myles, B.S.; Barnhill, G.P.; Hagiwara, T.; Griswold, D.E.; Simpson, R.L. A synthesis of studies on the intellectual, academic, social/emotional and sensory characteristics of children and youth with Asperger syndrome. Education and Training in Mental Retardation and Developmental Disabilities 2001, 36, 304-311.

77. Fernández-Herrero, J.; Lorenzo, G.; Lledó, A. A bibliometric study on the use of virtual reality (VR) as an educational tool for high-functioning autism spectrum disorder (ASD) children. In Contemporary perspective on child psychology and education, Çetinkaya, Ş., Ed.; IntechOpen: 2018; pp. 59-81.

78. Jang, J.; Matson, J.L.; Williams, L.W.; Tureck, K.; Goldin, R.L.; Cervantes, P.E. Rates of comorbid symptoms in children with ASD, ADHD, and comorbid ASD and ADHD. Res. Dev. Disabil. 2013, 34, 2369-2378, doi:10.1016/j.ridd.2013.04.021.

79. Vuilleumier, P. Facial expression and selective attention. Current Opinion in Psychiatry 2002, 15, 291-300, doi:10.1097/00001504200205000-00011.

80. Chita-Tegmark, M. Social attention in ASD: A review and meta-analysis of eye-tracking studies. Res. Dev. Disabil. 2016, 48, 7993, doi:10.1016/j.ridd.2015.10.011.

81. Parsons, S.; Mitchell, P. The potential of virtual reality in social skills training for people with autistic spectrum disorders. Journal of Intellectual Disability Research 2002, 46, 430-443, doi:10.1046/j.1365-2788.2002.00425.x.

82. Serret, S.; Hun, S.; Iakimova, G.; Lozada, J.; Anastassova, M.; Santos, A.; Vesperini, S.; Askenazy, F. Facing the challenge of teaching emotions to individuals with low- and high-functioning autism using a new serious game: A pilot study. Mol. Autism 2014, 5, 37, doi:10.1186/2040-2392-5-37.

83. Losh, M.; Capps, L. Narrative ability in high-functioning children with autism or asperger's syndrome. J. Autism Dev. Disord. 2003, 33, 239-251, doi:10.1023/A:1024446215446.

84. Shahab, M.; Taheri, A.; Mokhtari, M.; Shariati, A.; Heidari, R.; Meghdari, A.; Alemi, M. Utilizing social virtual reality robot (v2r) for music education to children with high-functioning autism. Education and Information Technologies 2021, doi:10.1007/s10639020-10392-0.

85. Gotham, K.; Brunwasser, S.M.; Lord, C. Depressive and anxiety symptom trajectories from school age through young adulthood in samples with autism spectrum disorder and developmental delay. J. Am. Acad. Child Adolesc. Psychiatry 2015, 54, 369-376.e363, doi:10.1016/j.jaac.2015.02.005.

86. Simpson, R.L.; de Boer-Ott, S.R.; Smith-Myles, B. Inclusion of learners with autism spectrum disorders in general education settings. Topics in Language Disorders 2003, 23, 116-133.

87. Williams, K.R. The son-rise program ${ }^{\circledR}$ intervention for autism: Prerequisites for evaluation. Autism 2006, 10, 86-102, doi:10.1177/1362361306062012.

88. Chaytor, N.; Schmitter-Edgecombe, M. The ecological validity of neuropsychological tests: A review of the literature on everyday cognitive skills. Neuropsychol. Rev. 2003, 13, 181-197, doi:10.1023/B:NERV.0000009483.91468.fb.

89. Burgess, P.W.; Alderman, N.; Forbes, C.; Costello, A.; M-acoates, L.; Dawson, D.R.; Anderson, N.D.; Gilbert, S.J.; Dumontheil, I.; Channon, $S$. The case for the development and use of "ecologically valid" measures of executive function in experimental and clinical neuropsychology. J. Int. Neuropsychol. Soc. 2006, 12, 194-209, doi:10.1017/S1355617706060310.

90. Parsons, T.D. Virtual reality for enhanced ecological validity and experimental control in the clinical, affective and social neurosciences. Front. Hum. Neurosci. 2015, 9, doi:10.3389/fnhum.2015.00660.

91. Neisser, U. Memory: What are the important questions. In Memory observed: Remembering in natural contexts, Neisser, U., Ed.; Freeman: San Francisco, 1982; pp. 3-19.

92. Banaji, M.R.; Crowder, R.G. The bankruptcy of everyday memory. American Psychologist 1989, 44, 1185-1193, doi:10.1037/0003066X.44.9.1185.

93. Didehbani, N.; Allen, T.; Kandalaft, M.; Krawczyk, D.; Chapman, S. Virtual reality social cognition training for children with high functioning autism. Comput. Human Behav. 2016, 62, 703-711, doi:10.1016/j.chb.2016.04.033.

94. Newbutt, N.; Sung, C.; Kuo, H.; Leahy, M.J. The potential of virtual reality technologies to support people with an autism condition: A case study of acceptance, presence and negative effects. Annual Review of Cybertherapy and Telemedicine 2016, 14, 149-154.

95. Cromby, J.; Standen, P.; Newman, J.; Tasker, H. Successful transfer to the real world of skills practised in a virtual environment by students with severe learning difficulties. In Proceedings of the Proceedings of the 1st International Conference on Disability, Virtual Reality and Associated Technologies (IDCVRAT), Reading, UK, 1996.

96. Wallace, S.; Parsons, S.; Westbury, A.; White, K.; White, K.; Bailey, A. Sense of presence and atypical social judgments in immersive virtual environments: Responses of adolescents with autism spectrum disorders. Autism 2010, 14, 199-213, doi:10.1177/1362361310363283.

97. Lahiri, U. Scope of virtual reality to autism intervention. In A computational view of autism; Springer: Cham, 2020; pp. 83-130.

98. Servotte, J.-C.; Goosse, M.; Campbell, S.H.; Dardenne, N.; Pilote, B.; Simoneau, I.L.; Guillaume, M.; Bragard, I.; Ghuysen, A. Virtual reality experience: Immersion, sense of presence, and cybersickness. Clinical Simulation in Nursing 2020, 38, 35-43, doi:10.1016/j.ecns.2019.09.006. 
99. Santhanam, S.p.; Hewitt, L.E. Perspectives of adults with autism on social communication intervention. Communication Disorders Quarterly 2021, 42, 156-165, doi:10.1177/1525740120905501.

100. Pallathra, A.A.; Calkins, M.E.; Parish-Morris, J.; Maddox, B.B.; Perez, L.S.; Miller, J.; Gur, R.C.; Mandell, D.S.; Schultz, R.T.; Brodkin, E.S. Defining behavioral components of social functioning in adults with autism spectrum disorder as targets for treatment. Autism Res. 2018, 11, 488-502, doi:10.1002/aur.1910.

101. Nijman, S.A.; Veling, W.; Greaves-Lord, K.; Vermeer, R.R.; Vos, M.; Zandee, C.E.R.; Zandstra, D.C.; Geraets, C.N.W.; Pijnenborg, G.H.M. Dynamic interactive social cognition training in virtual reality (discovr) for social cognition and social functioning in people with a psychotic disorder: Study protocol for a multicenter randomized controlled trial. BMC Psychiatry 2019, 19, 272, doi:10.1186/s12888-019-2250-0.

102. Cheng, Y.; Ye, J. Exploring the social competence of students with autism spectrum conditions in a collaborative virtual learning environment - the pilot study. Computers $\mathcal{E}$ Education 2010, 54, 1068-1077, doi:10.1016/j.compedu.2009.10.011.

103. Kuriakose, S.; Lahiri, U. Understanding the psycho-physiological implications of interaction with a virtual reality-based system in adolescents with autism: A feasibility study. IEEE Transactions on Neural Systems and Rehabilitation Engineering 2015, 23, 665675, doi:10.1109/TNSRE.2015.2393891.

104. Lahiri, U.; Bekele, E.; Dohrmann, E.; Warren, Z.; Sarkar, N. A physiologically informed virtual reality based social communication system for individuals with autism. J. Autism Dev. Disord. 2015, 45, 919-931, doi:10.1007/s10803-014-2240-5.

105. Cheng, Y.; Huang, C.-L.; Yang, C.-S. Using a 3D immersive virtual environment system to enhance social understanding and social skills for children with autism spectrum disorders. Focus Autism Other Dev. Disabl. 2015, 30, 222-236, doi:10.1177/1088357615583473.

106. Taryadi; Kurniawan, I. The improvement of autism spectrum disorders on children communication ability with pecs method multimedia augmented reality-based. Journal of Physics: Conference Series 2018, 947, 012009, doi:10.1088/1742-6596/947/1/012009.

107. Zapata-Fonseca, L.; Froese, T.; Schilbach, L.; Vogeley, K.; Timmermans, B. Sensitivity to social contingency in adults with highfunctioning autism during computer-mediated embodied interaction. Behavioral Sciences 2018, 8, doi:10.3390/bs8020022.

108. Lorenzo, G.; Pomares, J.; Lledó, A. Inclusion of immersive virtual learning environments and visual control systems to support the learning of students with Asperger syndrome. Computers \& Education 2013, 62, 88-101, doi:10.1016/j.compedu.2012.10.028.

109. Bernardini, S.; Porayska-Pomsta, K.; Sampath, H. Designing an intelligent virtual agent for social communication in autism. In Proceedings of the AAAI Conference on Artificial Intelligence and Interactive Digital Entertainment, Boston, Massachusetts, USA, 14-18 October 2013.

110. Porayska-Pomsta, K.; Anderson, K.; Bernardini, S.; Guldberg, K.; Smith, T.; Kossivaki, L.; Hodgins, S.; Lowe, I. Building an intelligent, authorable serious game for autistic children and their carers. In Proceedings of the Advances in Computer Entertainment, Cham, 2013; pp. 456-475.

111. Burke, S.L.; Bresnahan, T.; Li, T.; Epnere, K.; Rizzo, A.; Partin, M.; Ahlness, R.M.; Trimmer, M. Using virtual interactive training agents (vita) with adults with autism and other developmental disabilities. J. Autism Dev. Disord. 2018, 48, 905-912, doi:10.1007/s10803-017-3374-z.

112. Smith, M.J.; Ginger, E.J.; Wright, M.; Wright, K.; Boteler Humm, L.; Olsen, D.; Bell, M.D.; Fleming, M.F. Virtual reality job interview training for individuals with psychiatric disabilities. Journal of Nervous and Mental Disease 2014, 202, 659-667, doi:10.1097/NMD.0000000000000187.

113. Smith, M.J.; Ginger, E.J.; Wright, K.; Wright, M.A.; Taylor, J.L.; Boteler Humm, L.; Olsen, D.E.; Bell, M.D.; Fleming, M.F. Virtual reality job interview training in adults with autism spectrum disorder. J. Autism Dev. Disord. 2014, 44, 2450-2463, doi:10.1007/s10803-014-2113-y.

114. Smith, M.J.; Fleming, M.F.; Wright, M.A.; Losh, M.; Boteler Humm, L.; Olsen, D.; Bell, M.D. Brief report: Vocational outcomes for young adults with autism spectrum disorders at six months after virtual reality job interview training. J. Autism Dev. Disord. 2015, 45, 3364-3369, doi:10.1007/s10803-015-2470-1.

115. Strickland, D.C.; Coles, C.D.; Southern, L.B. Jobtips: A transition to employment program for individuals with autism spectrum disorders. J. Autism Dev. Disord. 2013, 43, 2472-2483, doi:10.1007/s10803-013-1800-4.

116. Yang, Y.J.D.; Allen, T.; Abdullahi, S.M.; Pelphrey, K.A.; Volkmar, F.R.; Chapman, S.B. Neural mechanisms of behavioral change in young adults with high-functioning autism receiving virtual reality social cognition training: A pilot study. Autism Res. 2018, 11, 713-725, doi:10.1002/aur.1941.

117. Russo-Ponsaran, N.; McKown, C.; Johnson, J.; Russo, J.; Crossman, J.; Reife, I. Virtual environment for social information processing: Assessment of children with and without autism spectrum disorders. Autism Res. 2018, 11, 305-317, doi:10.1002/aur.1889.

118. Stichter, J.P.; Laffey, J.; Galyen, K.; Herzog, M. Isocial: Delivering the social competence intervention for adolescents (SCI-A) in a 3D virtual learning environment for youth with high functioning autism. J. Autism Dev. Disord. 2014, 44, 417-430, doi:10.1007/s10803-013-1881-0.

119. Zhang, L.; Warren, Z.; Swanson, A.; Weitlauf, A.; Sarkar, N. Understanding performance and verbal-communication of children with ASD in a collaborative virtual environment. J. Autism Dev. Disord. 2018, 48, 2779-2789, doi:10.1007/s10803-018-3544-7.

120. Zhang, L.; Weitlauf, A.S.; Amat, A.Z.; Swanson, A.; Warren, Z.E.; Sarkar, N. Assessing social communication and collaboration in autism spectrum disorder using intelligent collaborative virtual environments. J. Autism Dev. Disord. 2020, 50, 199-211, doi:10.1007/s10803-019-04246-z. 
121. Zhao, H.; Swanson, A.R.; Weitlauf, A.S.; Warren, Z.E.; Sarkar, N. Hand-in-hand: A communication-enhancement collaborative virtual reality system for promoting social interaction in children with autism spectrum disorders. IEEE Transactions on HumanMachine Systems 2018, 48, 136-148, doi:10.1109/THMS.2018.2791562.

122. Castelli, F. Understanding emotions from standardized facial expressions in autism and normal development. Autism 2005, 9 , 428-449, doi:10.1177/1362361305056082.

123. Baron-Cohen, S.; Golan, O.; Ashwin, E. Can emotion recognition be taught to children with autism spectrum conditions? Philosophical Transactions of the Royal Society B: Biological Sciences 2009, 364, 3567-3574, doi:10.1098/rstb.2009.0191.

124. Lorenzo, G.; Lledó, A.; Pomares, J.; Roig, R. Design and application of an immersive virtual reality system to enhance emotional skills for children with autism spectrum disorders. Computers $\mathcal{E}$ Education 2016, 98, 192-205, doi:10.1016/j.compedu.2016.03.018.

125. Yang, Y.J.D.; Allen, T.; Abdullahi, S.M.; Pelphrey, K.A.; Volkmar, F.R.; Chapman, S.B. Brain responses to biological motion predict treatment outcome in young adults with autism receiving virtual reality social cognition training: Preliminary findings. Behaviour Research and Therapy 2017, 93, 55-66, doi:10.1016/j.brat.2017.03.014.

126. Ke, F.; Im, T. Virtual-reality-based social interaction training for children with high-functioning autism. The Journal of Educational Research 2013, 106, 441-461, doi:10.1080/00220671.2013.832999.

127. Ip, H.H.S.; Wong, S.W.L.; Chan, D.F.Y.; Byrne, J.; Li, C.; Yuan, V.S.N.; Lau, K.S.Y.; Wong, J.Y.W. Virtual reality enabled training for social adaptation in inclusive education settings for school-aged children with autism spectrum disorder (ASD). In Proceedings of the Blended Learning: Aligning Theory with Practices, Cham, 2016; pp. 94-102.

128. Schwarze, A.; Freude, H.; Niehaves, B. Advantages and propositions of learning emotion recognition in virtual reality for people with autism. Stockholm \& Uppsala, Sweden, June 8-14, 2019.

129. Modugumudi, Y.R.; Santhosh, J.; Anand, S. Efficacy of collaborative virtual environment intervention programs in emotion expression of children with autism. Journal of Medical Imaging and Health Informatics 2013, 3, 321-325, doi:10.1166/jmihi.2013.1167.

130. Bekele, E.; Wade, J.; Bian, D.; Fan, J.; Swanson, A.; Warren, Z.; Sarkar, N. Multimodal adaptive social interaction in virtual environment (MASI-VR) for children with autism spectrum disorders (ASD). In Proceedings of the 2016 IEEE Virtual Reality (VR), Greenville, South Carolina, USA, 19-23 March, 2016; pp. 121-130.

131. Kim, K.; Rosenthal, M.Z.; Gwaltney, M.; Jarrold, W.; Hatt, N.; McIntyre, N.; Swain, L.; Solomon, M.; Mundy, P. A virtual joystick study of emotional responses and social motivation in children with autism spectrum disorder. J. Autism Dev. Disord. 2015, 45, 3891-3899, doi:10.1007/s10803-014-2036-7.

132. Kim, K.; Geiger, P.; Herr, N.; Rosenthal, M. The virtual reality emotion sensitivity test (v-rest): Development and construct validity. In Proceedings of the Association for Behavioral and Cognitive Therapies (ABCT) Conference, San Francisco, CA, November 18-21, 2010.

133. Kohls, G.; Chevallier, C.; Troiani, V.; Schultz, R.T. Social 'wanting' dysfunction in autism: Neurobiological underpinnings and treatment implications. J. Neurodev. Disord. 2012, 4, 10, doi:10.1186/1866-1955-4-10.

134. Chevallier, C.; Kohls, G.; Troiani, V.; Brodkin, E.S.; Schultz, R.T. The social motivation theory of autism. Trends Cogn. Sci. 2012, 16, 231-239, doi:10.1016/j.tics.2012.02.007.

135. Cleland, J.; Gibbon, F.E.; Peppé, S.J.E.; O'Hare, A.; Rutherford, M. Phonetic and phonological errors in children with high functioning autism and Asperger syndrome. Int. J. Speech Lang. Pathol. 2010, 12, 69-76, doi:10.3109/17549500903469980.

136. Bosseler, A.; Massaro, D.W. Development and evaluation of a computer-animated tutor for vocabulary and language learning in children with autism. J. Autism Dev. Disord. 2003, 33, 653-672, doi:10.1023/B:JADD.0000006002.82367.4f.

137. Saadatzi, M.N.; Pennington, R.C.; Welch, K.C.; Graham, J.H. Small-group technology-assisted instruction: Virtual teacher and robot peer for individuals with autism spectrum disorder. J. Autism Dev. Disord. 2018, 48, 3816-3830, doi:10.1007/s10803-0183654-2.

138. Taylor, B.A.; DeQuinzio, J.A. Observational learning and children with autism. Behav. Modif. 2012, 36, 341-360, doi:10.1177/0145445512443981.

139. Nubia, R.M.; Fabián, G.R.; Wilson, R.A.; Wilmer, P.B. Development of a mobile application in augmented reality to improve the communication field of autistic children at a neurorehabilitar clinic. In Proceedings of the 2015 Workshop on Engineering Applications - International Congress on Engineering (WEA), Bogota, Colombia, 28-30 Oct., 2015; pp. 1-6.

140. Chen, F.; Wang, L.; Peng, G.; Yan, N.; Pan, X. Development and evaluation of a 3-D virtual pronunciation tutor for children with autism spectrum disorders. PLoS One 2019, 14, e0210858, doi:10.1371/journal.pone.0210858.

141. Iacoboni, M.; Dapretto, M. The mirror neuron system and the consequences of its dysfunction. Nature Reviews Neuroscience 2006, 7, 942-951, doi:10.1038/nrn2024.

142. Loomis, J.M.; Blascovich, J.J.; Beall, A.C. Immersive virtual environment technology as a basic research tool in psychology. Behavior Research Methods, lnstruments, E Computers 1999, 31, 557-564, doi:10.3758/bf03200735.

143. de la Rosa, S.; Breidt, M. Virtual reality: A new track in psychological research. British Journal of Psychology 2018, 109, 427-430, doi:10.1111/bjop.12302.

144. Parsons, S. Authenticity in virtual reality for assessment and intervention in autism: A conceptual review. Educational Research Review 2016, 19, 138-157, doi:10.1016/j.edurev.2016.08.001.

145. Parsons, S.; Mitchell, P.; Leonard, A. Do adolescents with autistic spectrum disorders adhere to social conventions in virtual environments? Autism 2005, 9, 95-117, doi:10.1177/1362361305049032.

146. Kinateder, M.; Ronchi, E.; Nilsson, D.; Kobes, M.; Müller, M.; Pauli, P.; Mühlberger, A. Virtual reality for fire evacuation research. In Proceedings of the 2014 Federated Conference on Computer Science and Information Systems, Warsaw, Poland, September 7-10, 2014; pp. 313-321. 
147. Ip, H.H.S.; Wong, S.W.L.; Chan, D.F.Y.; Byrne, J.; Li, C.; Yuan, V.S.N.; Lau, K.S.Y.; Wong, J.Y.W. Enhance emotional and social adaptation skills for children with autism spectrum disorder: A virtual reality enabled approach. Computers $\mathcal{E}$ Education 2018, 117, 1-15, doi:10.1016/j.compedu.2017.09.010.

148. Michela, A.; van Rooij, M.M.J.W.; Klumpers, F.; van Peer, J.M.; Roelofs, K.; Granic, I. Reducing the noise of reality. Psychol. Inq. 2019, 30, 203-210, doi:10.1080/1047840X.2019.1693872.

149. Lanier, M.; Waddell, T.F.; Elson, M.; Tamul, D.J.; Ivory, J.D.; Przybylski, A. Virtual reality check: Statistical power, reported results, and the validity of research on the psychology of virtual reality and immersive environments. Comput. Human Behav. 2019, 100, 70-78, doi:10.1016/j.chb.2019.06.015.

150. Nowak, K.L.; Biocca, F. The effect of the agency and anthropomorphism on users' sense of telepresence, copresence, and social presence in virtual environments. Presence: Teleoperators and Virtual Environments 2003, 12, 481-494, doi:10.1162/105474603322761289.

151. Georgescu, A.L.; Kuzmanovic, B.; Roth, D.; Bente, G.; Vogeley, K. The use of virtual characters to assess and train non-verbal communication in high-functioning autism. Front. Hum. Neurosci. 2014, 8, doi:10.3389/fnhum.2014.00807.

152. Nowak, K.L. The influence of anthropomorphism and agency on social judgment in virtual environments. Journal of ComputerMediated Communication 2004, 9, JCMC925, doi:10.1111/j.1083-6101.2004.tb00284.x.

153. Bryant, L.; Brunner, M.; Hemsley, B. A review of virtual reality technologies in the field of communication disability: Implications for practice and research. Disability and Rehabilitation: Assistive Technology 2020, 15, 365-372, doi:10.1080/17483107.2018.1549276.

154. Stanney, K.M.; Kennedy, R.S.; Drexler, J.M. Cybersickness is not simulator sickness. Proceedings of the Human Factors and Ergonomics Society Annual Meeting 1997, 41, 1138-1142, doi:10.1177/107118139704100292.

155. Spiegel, J.S. The ethics of virtual reality technology: Social hazards and public policy recommendations. Sci. Eng. Ethics 2018, 24, 1537-1550, doi:10.1007/s11948-017-9979-y.

156. Madary, M.; Metzinger, T. Recommendations for good scientific practice and the consumers of VR-technology. Frontiers in Robotics and AI 2016, 3, doi:10.3389/frobt.2016.00003.

157. Golding, J.F. Motion sickness susceptibility questionnaire revised and its relationship to other forms of sickness. Brain Res. Bull. 1998, 47, 507-516, doi:10.1016/S0361-9230(98)00091-4.

158. Dechsling, A.; Orm, S.; Kalandadze, T.; Sütterlin, S.; Øien, R.A.; Shic, F.; Nordahl-Hansen, A. Virtual and augmented reality in social skills interventions for individuals with autism spectrum disorder: A scoping review. J. Autism Dev. Disord. 2021, doi:10.1007/s10803-021-05338-5.

159. Frankel, F.; Whitham, C. Parent-assisted group treatment for friendship problems of children with autism spectrum disorders. Brain Res. 2011, 1380, 240-245, doi:10.1016/j.brainres.2010.09.047.

160. Schreibman, L.; Anderson, A. Focus on integration: The future of the behavioral treatment of autism. Behav. Ther. 2001, 32, 619632, doi:10.1016/S0005-7894(01)80012-5.

161. Lovaas, O.I. Behavioral treatment and normal educational and intellectual functioning in young autistic children. J. Consult. Clin. Psychol. 1987, 55, 3-9, doi:10.1037/0022-006X.55.1.3.

162. Tomasello, M.; Farrar, M.J. Joint attention and early language. Child Development 1986, 57, 1454-1463, doi:10.2307/1130423.

163. Landa, R. Early communication development and intervention for children with autism. Mental Retardation and Developmental Disabilities Research Reviews 2007, 13, 16-25, doi:10.1002/mrdd.20134.

164. Thelen, E. Grounded in the world: Developmental origins of the embodied mind. Infancy 2000, 1, 3-28, doi:10.1207/S15327078IN0101_02.

165. Peppé, S.; McCann, J.; Gibbon, F.; O'Hare, A.; Rutherford, M. Receptive and expressive prosodic ability in children with highfunctioning autism. J. Speech. Lang. Hear. Res. 2007, 50, 1015-1028, doi:10.1044/1092-4388(2007/071).

166. Aguilar, L. Learning prosody in a video game-based learning approach. Multimodal Technologies and Interaction 2019, 3, 51, doi:10.3390/mti3030051.

167. Rhea, P.; Augustyn, A.; Klin, A.; Volkmar, F.R. Perception and production of prosody by speakers with autism spectrum disorders. J. Autism Dev. Disord. 2005, 35, 205-220, doi:10.1007/s10803-004-1999-1.

168. Iovannone, R.; Dunlap, G.; Huber, H.; Kincaid, D. Effective educational practices for students with autism spectrum disorders. Focus Autism Other Dev. Disabl. 2003, 18, 150-165, doi:10.1177/10883576030180030301.

169. Wang, X.; Wang, S.; Fan, Y.; Huang, D.; Zhang, Y. Speech-specific categorical perception deficit in autism: An event-related potential study of lexical tone processing in Mandarin-speaking children. Sci. Rep. 2017, 7, 43254, doi:10.1038/srep43254.

170. Lu, Y.-F. Tone processing and the acquisition of tone in Mandarin-and English-speaking typically developing children and children with autism spectrum disorder. Doctoral thesis, University College London, 2016.

171. Sharmin, M.; Hossain, M.M.; Saha, A.; Das, M.; Maxwell, M.; Ahmed, S. From research to practice: Informing the design of autism support smart technology. In Proceedings of the 2018 CHI Conference on Human Factors in Computing Systems, Montreal QC, Canada, 2018; p. Paper 102.

172. Stahmer, A.C.; Schreibman, L.; Cunningham, A.B. Toward a technology of treatment individualization for young children with autism spectrum disorders. Brain Res. 2011, 1380, 229-239, doi:10.1016/j.brainres.2010.09.043.

173. Nuske, H.J.; Vivanti, G.; Dissanayake, C. Are emotion impairments unique to, universal, or specific in autism spectrum disorder? A comprehensive review. Cognition and Emotion 2013, 27, 1042-1061, doi:10.1080/02699931.2012.762900.

174. Gernsbacher, M.A.; Morson, E.M.; Grace, E.J. Language development in autism. In Neurobiology of language, Hickok, G., Small, S.L., Eds.; Academic Press: San Diego, 2016; pp. 879-886. 
175. Harris, S.L.; Handleman, J.S.; Gordon, R.; Kristoff, B.; Fuentes, F. Changes in cognitive and language functioning of preschool children with autism. J. Autism Dev. Disord. 1991, 21, 281-290, doi:10.1007/BF02207325.

176. Mirzaei, M.R.; Ghorshi, S.; Mortazavi, M. Audio-visual speech recognition techniques in augmented reality environments. The Visual Computer 2014, 30, 245-257, doi:10.1007/s00371-013-0841-1.

177. Harvey, A.; McCrindle, R.J.; Lundqvist, K.; Parslow, P. Automatic speech recognition for assistive technology devices. In Proceedings of the ICDVRAT 2010: The Eighth International Conference on Disability Virtual Reality and Associated Technologies, Valparaiso, Chile, 31 Aug-2 Sept, 2010; pp. 273-282.

178. Moon, J.; Ke, F.; Sokolikj, Z. Automatic assessment of cognitive and emotional states in virtual reality-based flexibility training for four adolescents with autism. Br. J. Educat. Tech. 2020, 51, 1766-1784, doi:10.1111/bjet.13005.

179. Lombardo, M.V.; Lai, M.-C.; Baron-Cohen, S. Big data approaches to decomposing heterogeneity across the autism spectrum. Mol. Psychiatry 2019, 24, 1435-1450, doi:10.1038/s41380-018-0321-0.

180. Schroeder, J.H.; Desrocher, M.; Bebko, J.M.; Cappadocia, M.C. The neurobiology of autism: Theoretical applications. Res. Autism Spectr. Disord. 2010, 4, 555-564, doi:10.1016/j.rasd.2010.01.004. 